\title{
sciendo
}

\section{The influence of ecological concern on green purchase behavior}

\author{
Eva FONTES \\ DEGEIT, University of Aveiro, Portugal \\ António C. MOREIRA \\ DEGEIT,GOVCOPP, University of Aveiro, Portugal \\ amoreira@ua.pt \\ Vera Carlos \\ DEGEIT, University of Aveiro, Portugal
}

\begin{abstract}
The present paper seeks to address a gap in the literature regarding green marketing and examines the relationship between ecological concern, inward and outward environmental attitudes, purchasing behavior and environmental behavior as antecedents of green purchasing behavior. The data was gathered through an online survey carried out in Portugal with 530 valid answers. Structural Equation Modelling Partial Least Squares (SEM-PLS) was used to evaluate the model. A t-test was applied to identify differences between men and women. The results show that ecological concern, environmental attitude, environmental behavior and purchase intention are good predictors of green purchase behavior. Women scored higher than men on all variables, meaning that they are indeed superior environmentalists than men. Green purchase behavior is strongly influenced by both purchase intention and environmental behavior, so green brands should focus on targeting individuals that already take some actions in what concerns the environment, or to those who intend to do so.
\end{abstract}

Keywords: Green Marketing, Ecological Concern, Environmental Attitude, Environmental Behavior, Purchase Intention, Green Purchase Behavior.

Please cite the article as follows: Fontes, E., Moreira, A. C. and Carlos, V. (2021), "The influence of ecological convern on green purchase behavior", Management \& Marketing. Challenges for the Knowledge Society, Vol. 16, No. 3, pp. 246-267, DOI: 10.2478/mmcks-2021-0015.

\section{Introduction}

The growth of international concern with sustainability, green environment and clean technologies has sparked the importance of sustainable and green marketing. Sustainable marketing pays attention not only to the environment, but also to economic and social issues, while marketing has always been seen as an activity that incentivizes consumerism (Belz, 2006). This term evolved throughout the years to become known as 'green marketing', which aims to find a balance between the need for profit (the incentive to consumerism), and the broader needs of the environment and its protection (Gordon et al., 2011).

The increasing attention to environmental issues is already paying off, as people are becoming more aware and concerned about the sustainability of the environment 
(Sun et al., 2018). Moreover, research has shown that what people buy can affect the Earth's environmental balance (Papadopolous et al., 2010).

The concern about the environment has led some consumers to avoid purchasing products that are detrimental to the environment; these are known as 'green consumers'. For example, in Portugal consumers are increasingly becoming more concerned about the environment and aware of the limitations of natural resources (Paço \& Raposo, 2010). Moreover, although the Portuguese tend to support proenvironment policies, they often fail in translating environmental concerns into actions (Paço \& Raposo, 2009).

Various authors have studied ecological concern (EC) (Hirsh, 2010) and the different predictors of green purchase behavior (GPB) (Arslan et al., 2012; Trivedi et al., 2018). Attitudes towards the environment are also important because individuals tend to be concerned about the abusive growing behavior that the environment is suffering, as well as with the perceived need for social, legal and political changes that are necessary to protect the environment (Leonidou et al., 2010). However, individual and public attitudes are different and tend to have different outcomes, affecting differently pro-environmental behavior of consumers (Kaufmann et al., 2012; Kollmuss and Agyeman, 2002). As such, this paper seeks to address the relationship between ecological concern, inward and outward environmental attitudes, purchasing behavior and environmental behavior as antecedents of green purchasing behavior, filling this gap in green marketing literature. Complementarily, this paper also analyzes to what extent men and women are following the 'green trend' in terms of the above-referred variables. In order to do so, we analyze Portuguese consumers.

This paper is divided in seven sections. After the first section, which presents the introduction, section 2 introduces the topics relevant to the research: sustainability and sustainable marketing; ecological marketing and green marketing; green consumer; environmental consciousness and ecological concern; environmental attitude; environmental behavior; purchase intention and green purchase behavior. Section 3 states and justifies the research model and the hypotheses. Section 4 presents the chosen research method and section 5 presents the main results. Section 6 discusses the results and, finally, section 7 presents the main conclusions.

\section{Theoretical background}

Pollution, droughts, floods, global warming, species extinction and other rising issues, all connected to human actions, have resulted in concerned attention towards the environment and the need to rethink human habits and actions (Siyavooshi et al., 2019). The overexploitation of natural resources due to rapid economic growth has made consumers realize that the state of the environment is worsening, increasing the search for greener products (Chen \& Chai, 2010). Saha and Darnton (2005 p. 117) claim that "extensive environmental damage has been caused by continuous consumption, marketing, manufacturing, processing, discarding and polluting". Individuals are increasingly concerned with environmental protection and sustainable development (Sun et al., 2018), and research on the topic has proven that the purchases individuals make affect the Earth's environmental balance (Papadopolous et al., 2010).

Sustainability is gradually becoming a growing concern in our day-to-day lives, which led to a rising concern that resulted in the concept of Sustainable Marketing. Sustainable marketing has been identified with "building and maintaining sustainable relationships with customers, the social environment and the natural environment", always creating economic, environmental and social value (Belz, 2006 p. 139). 
Sustainable marketing is based on three pillars: people/planet/profit (Elkington, 1997). For Phipps et al. (2013 p. 1227), sustainable consumption is the "consumption that simultaneously optimizes the environmental, social, and economic consequences of acquisition, use and disposition in order to meet the needs of both current and future generations".

Focusing on the environment, two concepts arise, which are frequently mixed up: ecological marketing and green marketing. The concept of ecological marketing - "all marketing activities that have the aim of removing the consequences of already existing ecological problems" (Henion \& Kinnear, 1975 p. 75) - is generally connected to the most toxic and damaging industries, such as mining or chemicals (Papadas et al., 2017). On the other hand, green marketing is seen as the search for balance between the company's need to obtain profit and the broader need to protect the environment (Gordon et al., 2011). In other words, green marketing promotes ecologically safer products (Aman et al. 2012), while implying that consuming this type of products is necessary for the sake of the environment (Preko, 2017). Clearly, ecological marketing is reactive, i.e., removes consequences from already existing problems, whereas green marketing only focuses on the environmental aspects (Katrandjiev, 2016).

Aside green marketing, the growing awareness amongst the world population regarding pollution and the planet's degradation caused other related concepts to arise, parallel to the whole environmental protection movement (Lee, 2009). One of these new concepts is the green consumer, who is likely to engage in green behaviors (Paço \& Raposo, 2010). These kinds of consumers emerged in the late 1980s, and are characterized by a behavior that avoids the purchase of products that might: be detrimental for health or the environment; use a large amount of natural resources that is unmatched to its benefits; lead to a big accumulation of trash because of its packaging, additional features or a short life cycle (frequently disposable); need material from protected species or regions; involve animal cruelty; or have a negative influence in other countries or societies around the globe (Katrandjiev, 2016). According to Shaw and Newholm (2002 p. 167), green consumers are ethical consumers that "consider a range of ethical issues in their consumption choices". This type of customers has shown to be relying on environmentally responsible firms by showing positive attitude and purchase intention concerning their products (Sony et al., 2015). Sony and Ferguson (2017) even claim that consumers are adopting the green movement in a mainstream manner.

In what concerns the characteristics of green consumers, several studies have been developed in recent years. Regarding demographic characteristics, Hojnik, Ruzzler and Manolova (2019) state that green purchase intention is differently affected by different levels of education. Specifically, consumers with the lowest (i.e., elementary and/or high school) and highest education (specialization, MBA or PhD.) show higher purchase intention when compared to the ones with the education level in between (i.e., bachelor's degree). Panzone, Hilton, Sale and Cohen (2016) also found that individuals with university education show higher environmental concern, in comparison to other levels of education. On the other hand, Saleem, Eagle and Low (2018) found that consumers with a higher education level sow more eco-social behaviors.

Hojnik, Ruzzler and Manolova (2019) identified a relevant relationship between age and environmental commitment. They found that older consumers display higher environmental commitment (i.e., commitment to environmental protection, waste reduction, cost reduction and health benefits). They support that older consumers tend to be more oriented towards their own children and grandchildren, as well as their 
future on the planet. As such, as individuals age, their tendency to preserve the environment for future generations tends to increase. On the other hand, previous research found that young consumers are more concerned about the environment that the older ones (Panzone et al., 2016). Brochado, Teiga and Oliveira-Brochado (2017) evaluated the influence of age on ecologically conscious consumer behavior and concluded that older consumers tend to exhibit a more environmental behavior.

Still concerning demographic characteristics, women seem to have a better perception about eco-products (i.e., eco-products perform better, are better for the environment, use materials that are less harmful for the environment, and more trustworthy) than men. They also express higher pro-environmental attitudes (Panzone et al., 2016), greater environmental commitment compared to men, greater green purchase intention (Hojnik, Ruzzler and Manolova, 2019) and tend to buy more environmentally friendly products (Brochado, Teiga \& Oliveira-Brochado, 2017).

Environmental consciousness, or environmental concern, refers to the belief, position and level of concern of an individual regarding the environment (Said et al., 2003). Dunlap and Jones (2002) defined ecological concern as a combination of the awareness about environmental problems, with the willingness to be part of the solution. Zimmer et al. (1994) refer to ecological concern as a more general concept regarding an individual's feeling about different green issues; or a representation of the concern about pollution and natural resources (Van Liere \& Dunlap, 1980). For Hirsh (2010), environmental consciousness is one of the dimensions of ecological concern, together with a concern for the environment and a sense of the importance of its protection.

Environmental knowledge may be defined as what consumers know about the consequences that human behavior has on the ecosystem and on environmental problems (Kaufmann et al., 2012). According to Vicente-Molina et al. (2013), environmental knowledge is an individual's ability to identify elements related to environmental protection, such as symbols, concepts and patterns of behavior. Paço and Raposo (2009) consider individuals as environmental knowledgeable when they are informed about aspects such as 'greenhouse effect', 'acid rain' and 'ozone hole'. The authors also consider knowledge as a different concept than environmental concern, which is perceived as the "concern about the various aspects of pollution (air pollution, problem of ozone depletion, pollution caused by industries, etc.)" (Paço \& Raposo, 2009 p.371).

Kollmuss and Agyeman (2002 p. 253) define environmental awareness as "knowing the impact of human behavior on the environment". As such, environmental awareness differs from environmental knowledge for having not only a cognitive side (knowledge), but also an affective one (based on perception).

According to Khan and Kahn (2006), an attitude is an individual's response, favorable or unfavorable, towards a thing, object, place or phenomenon, and a predictor of behavior (Azjen, 1991). Taking this to the environmental realm, environmental attitude is the ability to evaluate the environment's condition with a certain level of (dis)agreement (Milfont \& Duckitt, 2010). Also referred to as environment-friendly consumer attitude, it is sometimes mixed up with environmental behavior, and defined as a set of environment-friendly activities an individual performs, such as recycling, energy conservation or environmental activism (McCarty \& Shrum, 2001).

Outward environmental attitude refers to the common action/effort perceived as necessary from different facets of the society, which is clearly a collective attitude, in order to protect the environment. Inward environment attitude is a person's attitude 
towards environmental issues, clearly an individual attitude (Leonidou et al., 2010). Inward environmental attitudes are "attitudes referring to the abuse of the environment by individual consumers" (p. 1322) and outward environmental attitudes are defined as "attitudes about the perceived need for social, political and legal changes to protect the environment" (Leonidou et al., 2010 p. 1322).

Different terms have been used in literature to refer to behavior concerning the environment. The most common ones are green behavior, pro-environmental behavior, environmentally friendly behavior, environmentally sustainable behavior and environmentally significant behavior. Pro-environmental behavior may be defined as "behavior that consciously seeks to minimize the negative impact of one's actions on the natural and built world" (Kollmuss \& Agyeman, 2002, p. 240). De Castro (2001) defines environmental behavior as the set of actions an individual takes part in, alone or in a group, with the purpose of improving the environment and conserving natural resources.

Green purchase behavior (GPB) is related to the purchase of green products (Jansson et al., 2010). There are usually two domains of pro-environmental behavior: the public and the private sphere (Stern et al., 1999). The public sphere includes proenvironmental activities and actions that are done publicly, such as activism, good citizenship, and support for environmental policies. The private sphere encompasses all behavior of purchase, consumption and disposal of personal and household products that impact the environment (Stern, 1999).

A green behavior goes beyond the attitudinal perspective. It is normally associated with the consumption of products that are in favor of - or that do not damage - the environment (Hasnah, 2014), while acting responsibly (Paço et al., 2019), or buying products that are environmentally beneficial (Mainieri et al., 1997). Fraj and Martinez (2006) have distinguished the concepts by stating that an ecological attitude is about the intention to act, which can be favorable or unfavorable, and that behavior requires a pattern of conduct.

When it comes to green conscious behavior, there are different motivations and perceptions regarding the human-nature relationship. These different perspectives are the so called 'environmental paradigms' (Dunlap \& Van Liere, 1978) or 'human-nature connectedness' (Burgh-Woodman and King, 2012), and divide the relationship in two views: the anthropocentric paradigm and the eco-centric paradigm. The anthropocentric paradigm sees mankind as the center piece, which means that it refers to the belief that the environment needs to be protected because of the value it has for humans (Domanska, 2011). On the other hand, the eco-centric paradigm might be considered more altruistic: it is the belief that, despite the utility is has for humans, the environment should be protected because of its inherent value (Bailey \& Wilson, 2009). Explaining further, some people see themselves as an integral part of the environment, a bigger thing that they cannot control, esteeming it despite its utility for humans, while other individuals see themselves as masters of the environment, thinking they control it (Perera \& Hewege, 2018).

Intention precedes behavior (Azjen, 1991). As referred to in the Theory of Planned Behavior (TPB) the intention represents the motivation of an individual to perform a given behavior, more specifically "how hard people are willing to try, (...) how much of an effort they are planning to exert, in order to perform the behavior" (Azjen, 1991 p.181).

Based on this concept, to the buying context, purchase intention is formed assuming there is a pending purchase/transaction, so it is normally considered a 
relevant indicator of actual purchase (Chang \& Wildt, 1994). Green purchase intention is defined as the motivation that an individual has to make an effort into practicing a GPB (Sheng et al., 2019). Intentions to perform a behavior are considered to better explain values and identity than actual past behavior (Qasim et al., 2019). According to Leonidou et al. (2010 p. 1237), GPB is the "preference and use of products that are friendly to the environment and/or have been produced using ecological processes and material". Sheng et al. (2019) define it as the purchase of products that are not only recyclable, but also environmentally friendly. Sun et al. (2018) claim that green buying behavior has a significant influence on sustainable development.

\section{Research model and hypotheses}

There is evidence that ecological concern motivates a more environmental attitude (Amanvet al., 2012) and that the higher the rate of ecological concern the higher the probability of showing eco-friendly behavior (Paço \& Raposo, 2009; Tang et al., 2014). Trivedi et al. (2018) studied inward and outward environmental attitude separately and showed that ecological concern influences both positively, leading to the following hypotheses:

$\mathbf{H}_{1}$ : Ecological concern positively influences inward environmental attitude.

$\mathbf{H}_{2}$ : Ecological concern positively influences outward environmental attitude.

It is expected that an individual with an environmental attitude would convert it into a behavior. Arslan et al. (2012) demonstrated that environmental attitude would positively influence environmental behavior. Dono et al. (2010) also found a significant relationship between environmental attitudes and behaviors. The relationship between the different types of attitude (inward and outward) and environmental behavior is still not widely studied, however Leonidou et al. (2010) supported that outward environmental attitude positively influences general environmental behavior. Hence, the following hypotheses are put forward:

$\mathbf{H}_{3}$ : Inward environmental attitude positively influences environmental behavior.

$\mathbf{H}_{4}$ : Outward environmental attitude positively influences environmental behavior.

Trivedi et al. (2018) sustain that inward environmental attitude positively influences purchase intention, although the relationship between outward environmental attitude and purchase intention was not tested. Environmental attitude as a whole has proven to positively influence the intention to buy green products (Schwepker \& Cornwell, 1991; Aman et al., 2012; Sun et al., 2018). As such, the next hypotheses are drawn:

$\mathbf{H}_{5}$ : Consumers' inward environmental attitude results in increased intention to purchase environment-friendly products.

H6: Consumers' outward environmental attitude results in increased intention to purchase environment-friendly products.

Although the TPB (Azjen, 1991) states that intention affects behavior, research has shown that environmental behaviors may lead to an intention to purchase environmentally-friendly products (Yarimoglu \& Binboga, 2018). Akehurst, Afonso, and Gonçalves (2012) also studied the influence of environmentally conscious consumer behavior on green purchase intention, which was proven to be significant. Therefore, the following hypothesis is put forward: 
H7: Environmental behavior results in increased intention to purchase environmentfriendly products.

There is a positive relationship between environmental behavior and environmentally conscious purchase behavior (Arslan et al., 2012). The authors also sustain that purchase behavior is an action towards protecting the environment, which connects to the definition of environmental behavior. Tamuliene et al. (2016) and Yarimoglu and Binboga (2018) also show that there is a strong relationship between ecological behavior and the purchase of ecological products, leading to the following hypothesis:

H8: Environmental behavior positively influences green purchase behavior.

As supported in various theories, namely by the TPB (Azjen, 1991), a behavior is positively influenced by an intention to act upon it. However, when it comes to green purchase behavior, things appear to happen differently. Research has shown that there is a gap between attitudes of consumers regarding the environment and actual GPB (Vermeir \& Verbeke, 2006), called 'value-action' or 'intention-behavior' gap. Despite these mixed results, several studies show a strong positive relationship between purchase intention and GPB (Chan, 2001; Trivedi et al., 2018), resulting in the subsequent hypothesis:

H9: Green purchase intention positively influences green purchase behavior.

Roberts (1996) claims that if a study regarding green customers fails to analyze demographic profiles - in this case, the gender aspect -, it is not reviewing environmentalism properly. Although earlier research presents men as more ecologically concerned than women, the study was performed in a very specific cultural context - Pakistan -, where women tend to have less active roles in society (Saleem et al., 2018). Other research support women as more ecologically concerned (Mohai, 1992; Rahim, et al., 2017), leading to the following hypothesis:

H10a: Women show higher levels of EC than men.

Previous research supports that women have stronger attitudes towards environmental quality (Diamantopoulos et al., 2003). Mainieri et al. (1997) also show that women are more pro-environmental than men. Hence, the following is hypothesized:

H10b: Women show higher levels of IEA than men.

H10c: Women show higher levels of OEA than men.

According to Roberts (1996), women display more environmental behaviors. Additional research shows that women carry out more environmental behaviors such as recycling (Mainieri et al., 1997; Diamantopoulos et al., 2003). Consequently, the next hypothesis is put forward:

H10d: Women show higher levels of environmental behavior than men.

Although Deliana and Rum (2019) found no differences in the behavior of men and women regarding green consumption, according to Baker and Ozaki (2008), gender is an important predictor of attitude towards GPB. Females are more likely to have green purchase intention than males (Rahim, et al., 2017; Hojnik, Ruzzler and Manolova, 2019). Roberts (1996) claims that women represent the majority of green customers 
and are more likely to buy specific products because they think they are better for the environment (Mainieri et al., 1997). Also, Diamantopoulos et al. (2003) support that females have 'greener shopping habits' than males, leading to the following hypotheses:

H10e: Women show higher levels of PI than men.

H10f: Women show higher levels of GPB than men.

Figure 1 presents the model and the aforementioned hypotheses.

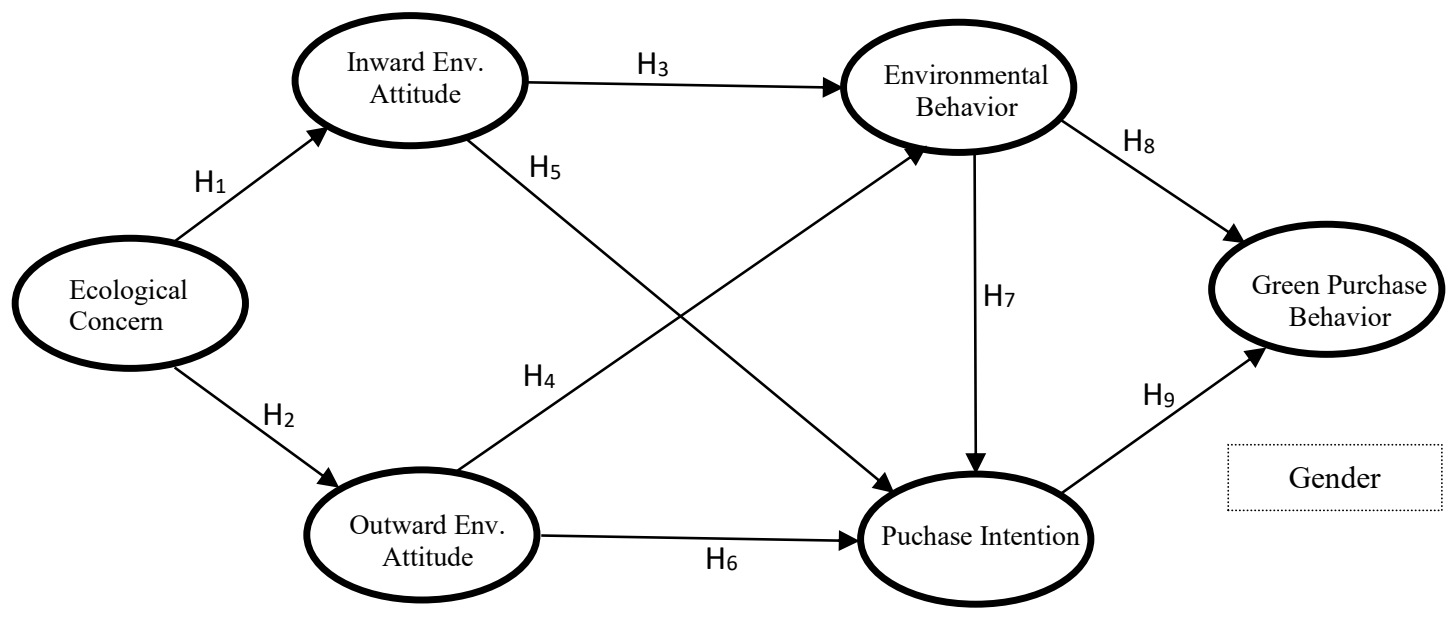

Figure 1. Research model

Source: Authors'

\section{Research Methods}

Data was collected between April 2019 and May 2019, using a survey questionnaire that included adapted scales validated in previous research. After the literature review, an online survey in Portuguese was created.

The survey was created using the Google Forms tool (available in Portuguese at https://forms.gle/ossRowF7E6WtoZXq9), which allows the online data collection and automatically groups all the information in a database.

A pretest with ten respondents was conducted, both men and women, and of different ages, in order to identify potential mistakes and to make the survey as simple to understand as possible. This convenience sample was useful to verify the questionnaire organization, formatting and proper wording of questions, if respondents understood the questions and how much time was necessary to answer the survey. This helped in the elimination of some errors and minor changes were made before releasing the final version.

The target population of this study consisted of Portuguese individuals who could be easily reached through online channels. As such, the survey was sent via email to different universities in the country, and also shared on social networks. It was online during one month and we gathered a total of 530 valid answers. An online survey was the chosen medium for this research for allowing fast and free data collection. Another advantage is that it allows respondents to answer whenever they want.

The survey was divided into three parts: the first explaining the purpose of the research and asking for the respondent's willingness to participate; the second one included all other environmental variables; and the last one contained sociodemographic questions. 
All questions, besides the sociodemographic ones, were asked using a five-point Likert scale, which allows for direction measuring (if the respondent agrees or disagrees) and intensity ('strongly' or not) (Albaum, 1997). In this case, 1 meant 'totally disagree' and 5 'totally agree'.

The scale for Environmental Behavior (EB) was adapted from Arslan et al. (2012) and consisted of seven items. All other constructs were adapted from Trivedi et al. (2018). The scale for EC consisted of five items; the scales IEA and OEA consisted of four and three items, respectively; PI consisted of three items and GPB consisted of four items. Item B2 of the EC scale was adapted since it was equal to item D3 of OEA original scale; the adaptation maintained the same objective/meaning (see the original versions of the scales in Appendix A).

As all scales where initially in English, they were translated to Portuguese and back translated to English by different individuals until the same meaning/understanding was achieved (Douglas \& Craig, 2007).

To analyze the data, the Statistical Package for the Social Sciences (SPSS) software, version 25.0, was used, as well as Partial Least Squares Structural Equation Modeling (PLS-SEM). This methodology is justified by its robust results when nonnormal data is used and when research is at an early stage of theoretical development, that is, when researchers seek to test and validate an exploratory model (Chin, 1998; Henseler \& Chin, 2010).

The first steps in the analysis aimed to check the model consistency. For this purpose, the following methods were used: reliability analysis, in order to validate the scales, and Exploratory Factor Analysis (EFA). According to Curran, West, and Finch (1996), the skewness and kurtosis should be lower than $|2.0|$ and $|7.0|$, respectively, in order to prove the sample's severe non-normality. Based on the results achieved for each item, data were treated as normal data.

For the reliability analysis, the Cronbach Alpha reference values presented by Pestana and Gageiro (2014) were used. T-tests were used to compare means between genders.

PLS-SEM includes one or more linear regression equations to express the linear causal relationship between independent (exogenous) and dependent (endogenous) constructs. The main purpose of this type of analysis is to measure the links between latent constructs (Reisinger and Turner, 1999). SEM is generally used for theory testing, to specify and test alternative causal relationships (Arslan et al., 2012).

\section{Results}

The sample includes a total of 530 individuals (Table 1). The vast majority are women $(77.7 \%)$, with 412 answers. The most representative age group is the one from 19 to 24 years of age (38.3\%), with 203 respondents. The least representative group is the one that includes individuals up to 18 years old $(0.4 \%)$, with only 2 respondents. Individuals that are 25 to 34 years old are included in the second most representative group (27.2\%; $\mathrm{N}=144)$. The age groups from 35 to 44 and 45 to 54 represent, respectively, $12.8 \%(\mathrm{~N}=68)$ and $11.3 \%(\mathrm{~N}=60)$ of the sample. Individuals aged between 55 and 64 represent $8.3 \%$ of the total $(\mathrm{N}=44)$. Finally, the group age 65 or over includes 9 individuals $(1.7 \%)$.

Table 1. Demographic Data

\begin{tabular}{|c|c|c|}
\hline Gender & Frequency & Percentage \\
\hline Feminine & 412 & $77.7 \%$ \\
\hline
\end{tabular}




\begin{tabular}{|l|c|c|}
\hline Masculine & 116 & $21.9 \%$ \\
\hline Other & 2 & $0.4 \%$ \\
\hline
\end{tabular}

Source: Authors' own research.

The results of the reliability analysis confirm the internal consistency of the scales. Before running the PLS-SEM software, an EFA was run to assure the consistency of the scale.

Table 2 shows the loadings and cross-loadings for the items. The t-values were obtained by bootstrapping with 2000 iterations, indicating that all loadings are statistically significant at the $1 \%$ level of significance ( $\mid$ t-values $\mid \geq 3.291$ ). Items B2, C3, E2 and G4 had lower loadings than the minimum recommended of 0.7 (Götz et al., 2010). While these items were not excluded during EFA, an outer loading relevance testing was performed at this stage. As such, in the case of outer loadings between 0.40 and 0.70 , the impact of the deletion on AVE and CR was measured, and the reflective indicator was deleted if an increase above threshold was seen in the measures by performing the deletion (Hair et al., 2016).

Table 2. Loadings and Cross-Loadings using PLS-SEM

\begin{tabular}{ccccccc}
\hline & $E C$ & $E B$ & $G P B$ & $I E A$ & $O E A$ & $P I$ \\
\hline$B 1$ & $\mathbf{0 . 8 3 4}$ & 0.642 & 0.590 & 0.761 & 0.518 & 0.607 \\
$B 2$ & $\mathbf{0 . 6 3 6}$ & 0.144 & 0.149 & 0.292 & 0.480 & 0.202 \\
$B 5$ & $\mathbf{0 . 7 4 4}$ & 0.298 & 0.335 & 0.430 & 0.464 & 0.411 \\
$C 1$ & 0.721 & 0.618 & 0.581 & $\mathbf{0 . 8 3 5}$ & 0.500 & 0.608 \\
$C 2$ & 0.563 & 0.532 & 0.518 & $\mathbf{0 . 8 2 2}$ & 0.552 & 0.571 \\
$C 3$ & 0.384 & 0.418 & 0.417 & $\mathbf{0 . 6 5 5}$ & 0.329 & 0.433 \\
$C 4$ & 0.475 & 0.527 & 0.493 & $\mathbf{0 . 7 5 5}$ & 0.427 & 0.555 \\
$D 1$ & 0.564 & 0.358 & 0.335 & 0.529 & $\mathbf{0 . 8 9 6}$ & 0.464 \\
$D 2$ & 0.510 & 0.316 & 0.278 & 0.504 & $\mathbf{0 . 8 7 1}$ & 0.441 \\
$D 3$ & 0.621 & 0.373 & 0.329 & 0.523 & $\mathbf{0 . 8 5 0}$ & 0.478 \\
$E 1$ & 0.483 & $\mathbf{0 . 7 4 2}$ & 0.553 & 0.598 & 0.441 & 0.544 \\
$E 3$ & 0.310 & $\mathbf{0 . 7 6 2}$ & 0.601 & 0.422 & 0.199 & 0.514 \\
$E 4$ & 0.409 & $\mathbf{0 . 8 4 1}$ & 0.620 & 0.536 & 0.280 & 0.564 \\
$E 5$ & 0.470 & $\mathbf{0 . 8 5 9}$ & 0.655 & 0.620 & 0.326 & 0.634 \\
$E 6$ & 0.469 & $\mathbf{0 . 7 6 8}$ & 0.551 & 0.546 & 0.345 & 0.564 \\
$F 1$ & 0.510 & 0.688 & 0.739 & 0.661 & 0.399 & $\mathbf{0 . 8 7 9}$ \\
$F 2$ & 0.464 & 0.463 & 0.496 & 0.510 & 0.517 & $\mathbf{0 . 7 8 9}$ \\
$F 3$ & 0.513 & 0.625 & 0.649 & 0.613 & 0.453 & $\mathbf{0 . 8 6 7}$ \\
$G 1$ & 0.518 & 0.713 & $\mathbf{0 . 9 0 7}$ & 0.628 & 0.364 & 0.765 \\
$G 2$ & 0.386 & 0.560 & $\mathbf{0 . 8 3 4}$ & 0.500 & 0.250 & 0.561 \\
$G 3$ & 0.458 & 0.666 & $\mathbf{0 . 8 6 4}$ & 0.576 & 0.315 & 0.618 \\
\hline
\end{tabular}

Source: Authors' own research.

Table 3 presents the average variance extracted (AVE), composite reliability (CR), and correlations of each latent variable. All CR values are above the expected minimum of 0.6 by Götz et al. (2010), which indicates that the constructs have adequate internal consistency. Regarding AVE, it is also higher than the recommended minimum of 0.5 (Götz et al., 2010), which confirms their convergent validity. Also, in Table 3, the square root of each construct's AVE is in bold. Since this number is higher than the absolute value of all correlations with other constructs in all cases, discriminant validity is verified. This is also reinforced by the fact that, in Table 2, the cross-loadings are lower than the loadings for all items (Götz et al., 2010).

Figure 2 shows the structural model that was evaluated: firstly, in terms of sign, magnitude, and statistical significance of the parameters of structural relations, and 
secondly, the explained variance $\left(\mathrm{R}^{2}\right)$ of the endogenous latent variables was also used to evaluate the structural model (Götz et al., 2010).

Table 3. CR, AVE, and Correlations among latent variables

\begin{tabular}{lcccccccc}
\hline & \multirow{8}{*}{ AVE } & \multirow{8}{*}{ Correlations } \\
& & & 1 & 2 & 3 & 4 & 5 & 6 \\
\hline 1. EC & 0.786 & 0.553 & $\mathbf{0 . 7 4 3}$ & & & & & \\
2. EB & 0.889 & 0.575 & 0.541 & $\mathbf{0 . 7 9 6}$ & & & & \\
3. GPB & 0.875 & 0.640 & 0.528 & 0.750 & $\mathbf{0 . 8 6 9}$ & & & \\
4. IEA & 0.852 & 0.593 & 0.714 & 0.688 & 0.658 & $\mathbf{0 . 7 7 0}$ & & \\
5. OEA & 0.906 & 0.762 & 0.651 & 0.404 & 0.361 & 0.595 & $\mathbf{0 . 8 7 3}$ & \\
6. PI & 0.883 & 0.716 & 0.586 & 0.711 & 0.754 & 0.710 & 0.530 & $\mathbf{0 . 8 4 6}$ \\
\hline
\end{tabular}

Source: Authors' own research.

As one can see on Figure 2, not all structural relationships have parameters compatible with the assumptions made in the research model. The relationships of EC with IEA and OEA are both significant at a 1\% level of significance, with a $\beta$ value of 0.714 and 0.651 , respectively. IEA also relates positively and significantly to both EB and PI, with $\beta$ values of 0.696 and 0.315 , respectively. OEA relates negatively and not significantly to EB ( $\beta=-0.013)$, and positively to PI $(\beta=0.172)$. EB also has a significant relationship with PI $(\beta=0.432)$. Both EB and PI have a positive influence in GPB, with $\beta$ values of 0.425 and 0.447 , respectively. These results do not support $\mathrm{H}_{4}$, as shown in Table 4.

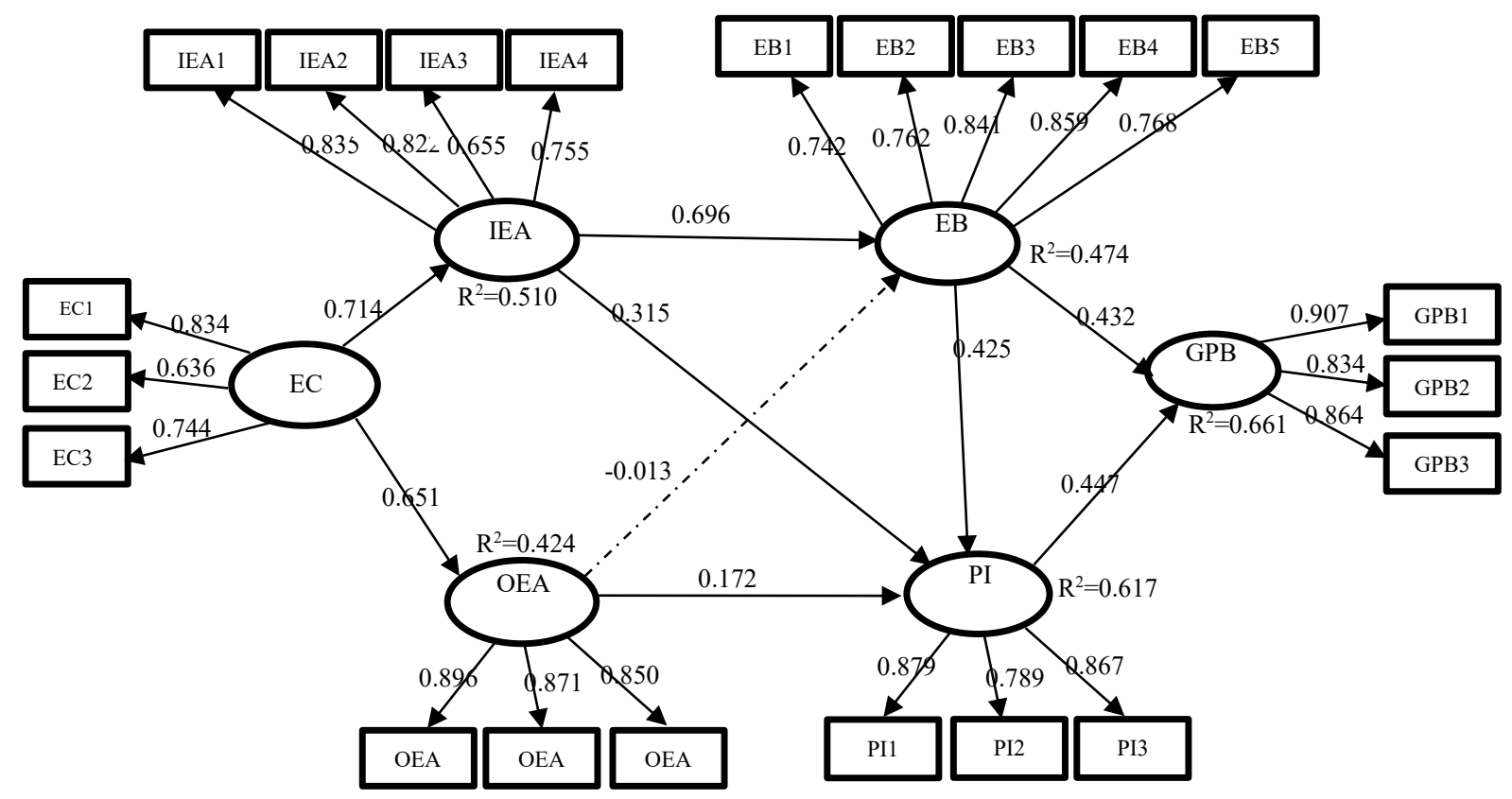

Figure 1. Results of structural model

Source: Authors'

According to $\mathrm{Hu}$ and Bentler (1998) a model needs to have a SRMR 0.10 (or lower than 0.08 in a more conservative version) to have a good fit. The SRMR value for this model was 0.086 . As such, one can consider that it has a proper goodness of fit to avoid model misspecification.

One can conclude that $66.1 \%$ of GPB is explained by its antecedents. While $51 \%$ of IEA was explained by EC, only $42.4 \%$ of OEA is explained by EC. $61.7 \%$ of PI is 
explained by its antecedents: EC, IEA, OEA and EB. Moreover, as shown in Table 5, there is an important indirect effect of $\mathrm{EC}(\beta=0.454)$ on GPB. EB is the most important variable influencing GPB $(\beta=0.622)$ with a direct influence $(\beta=0.432)$ more prevalent than its indirect influence $(\beta=0.190)$. If there is an important direct effect $(\beta=0.447)$ played by PI on GPB, the indirect effect of IEA is very strong $(\beta=0.574)$. As such one can claim that EC, IEA, EB and PI play a crucial role on GPB.

Table 4. Confirmation of General Hypotheses

\begin{tabular}{lcccc}
\hline Relation & $\beta_{\mathbf{i}}$ & p-value & Hypothesis & Validated \\
\hline EC -> IEA & 0.714 & $\mathbf{0 . 0 0 0}$ & $\mathbf{H}_{\mathbf{1}}$ & YES \\
EC -> OEA & 0.651 & $\mathbf{0 . 0 0 0}$ & $\mathbf{H}_{\mathbf{2}}$ & YES \\
IEA -> EB & 0.696 & $\mathbf{0 . 0 0 0}$ & $\mathbf{H}_{\mathbf{3}}$ & YES \\
OEA -> EB & -0.013 & $\mathbf{0 . 7 6 1}$ & $\mathbf{H}_{\mathbf{4}}$ & NO \\
IEA -> PI & 0.315 & $\mathbf{0 . 0 0 0}$ & $\mathbf{H}_{\mathbf{5}}$ & YES \\
OEA -> PI & 0.172 & $\mathbf{0 . 0 0 0}$ & $\mathbf{H}_{\mathbf{6}}$ & YES \\
EB -> PI & 0.425 & $\mathbf{0 . 0 0 0}$ & $\mathbf{H}_{\mathbf{7}}$ & YES \\
EB -> GPB & 0.432 & $\mathbf{0 . 0 0 0}$ & $\mathbf{H}_{\mathbf{8}}$ & YES \\
PI -> GPB & 0.447 & $\mathbf{0 . 0 0 0}$ & $\mathbf{H}_{\mathbf{9}}$ & YES \\
\hline
\end{tabular}

Source: Authors' own research.

Table 5. Direct, Indirect and Total Effects

\begin{tabular}{lcccccc}
\hline & \multicolumn{2}{c}{ Direct Effects } & \multicolumn{2}{c}{ Indirect Effects } & \multicolumn{2}{c}{ Total Effects } \\
\hline & $\begin{array}{c}\text { Path } \\
\text { Coefficient }\end{array}$ & $\begin{array}{c}\mathrm{p}- \\
\text { values }\end{array}$ & $\begin{array}{c}\text { Path } \\
\text { Coefficient }\end{array}$ & $\begin{array}{c}\text { p- } \\
\text { values }\end{array}$ & $\begin{array}{c}\text { Path } \\
\text { Coefficient }\end{array}$ & $\begin{array}{c}\text { p- } \\
\text { values }\end{array}$ \\
\hline EC -> EB & & & 0.488 & 0.000 & 0.488 & 0.000 \\
EC -> GPB & & & 0.454 & 0.000 & 0.454 & 0.000 \\
EC -> IEA & 0.714 & 0.000 & & & 0.714 & 0.000 \\
EC -> OEA & 0.651 & 0.000 & & & 0.651 & 0.000 \\
EC -> PI & & & 0.544 & 0.000 & 0.544 & 0.000 \\
EB -> GPB & 0.432 & 0.000 & 0.190 & 0.000 & 0.622 & 0.000 \\
EB -> PI & 0.425 & 0.000 & & & 0.425 & 0.000 \\
IEA -> EB & 0.696 & 0.000 & & & 0.696 & 0.000 \\
IEA -> GPB & & & 0.574 & 0.000 & 0.574 & 0.000 \\
IEA -> PI & 0.315 & 0.000 & 0.216 & 0.000 & 0.611 & 0.000 \\
OEA -> EB & -0.013 & 0.761 & & & -0.026 & 0.761 \\
OEA -> GPB & & & 0.069 & 0.113 & 0.069 & 0.113 \\
OEA -> PI & 0.172 & 0.000 & -0.005 & 0.542 & 0.166 & 0.000 \\
PI -> GPB & 0.447 & 0.000 & & & 0.447 & 0.000 \\
\hline
\end{tabular}

Source: Authors' own research.

Table 6 shows that women present higher means than men for all constructs. This supports all hypotheses presented regarding gender.

Table 6. Descriptive statistics for comparison between gender

\begin{tabular}{|c|c|c|c|c|c|c|c|}
\hline Variable & Gender & $\mathbf{N}$ & Mean & $\begin{array}{c}\text { Mean } \\
\text { Difference }\end{array}$ & p-value & Hipothesis & Validation \\
\hline EC & $\begin{array}{c}\text { Female } \\
\text { Male }\end{array}$ & $\begin{array}{l}412 \\
116\end{array}$ & $\begin{array}{l}4.4494 \\
4.1184\end{array}$ & 0.3310 & 0.000 & $\mathrm{H}_{10 \mathrm{a}}: \mathrm{EC}_{\mathrm{F}}>\mathrm{EC}_{\mathrm{M}}$ & Yes \\
\hline IEA & $\begin{array}{l}\text { Female } \\
\text { Male }\end{array}$ & $\begin{array}{l}412 \\
116\end{array}$ & $\begin{array}{l}4.2139 \\
3.8603\end{array}$ & 0.3535 & 0.000 & $\mathrm{H}_{10 \mathrm{~b}}: \mathrm{IEA}_{\mathrm{F}}>\mathrm{IEAM}_{\mathrm{M}}$ & Yes \\
\hline OEA & $\begin{array}{l}\text { Female } \\
\text { Male }\end{array}$ & $\begin{array}{l}412 \\
116\end{array}$ & $\begin{array}{l}4.7364 \\
4.4231\end{array}$ & 0.3133 & 0.000 & $\mathrm{H}_{10 c:} \mathrm{OEAF}_{\mathrm{F}}>\mathrm{OEAM}$ & Yes \\
\hline EB & $\begin{array}{l}\text { Female } \\
\text { Male }\end{array}$ & $\begin{array}{l}412 \\
116 \\
\end{array}$ & $\begin{array}{l}3.5983 \\
3.2075\end{array}$ & 0.3907 & 0.000 & $\mathrm{H}_{10 \mathrm{~d}}: \mathrm{EB}_{\mathrm{F}}>\mathrm{EB}_{\mathrm{M}}$ & Yes \\
\hline PI & Female & 412 & 4.3023 & 0.3907 & 0.000 & $\mathrm{H}_{10 \mathrm{e}}: \mathrm{PI}_{\mathrm{F}}>\mathrm{PI}_{\mathrm{M}}$ & Yes \\
\hline
\end{tabular}




\begin{tabular}{cccccccc}
\hline Variable & Gender & N & Mean & $\begin{array}{c}\text { Mean } \\
\text { Difference }\end{array}$ & p-value & Hipothesis & Validation \\
\hline \multirow{2}{*}{ GPB } & Male & 116 & 3.7789 & & & \\
& Female & 412 & 3.9465 & 0.3896 & 0.000 & $\mathrm{H}_{10 \mathrm{f}}: \mathrm{GPB}_{\mathrm{F}}>\mathrm{GPB}_{\mathrm{M}}$ & Yes \\
\hline
\end{tabular}

Source: Authors' own research.

\section{Discussion}

In line with earlier research, environmental concern was found to positively influence both inward and outward environmental attitude (Arslan et al., 2012; Aman et al., 2012; Tang et al., 2014; Trivedi et al., 2018). This means that individuals who are more conscious about nature and humans' impact on the environment urge for political and social change and are willing to do something about it, such as recycling, reducing their consumption, and donating money to environmental causes (Trivedi et al., 2018).

Although the TPB defends attitudes as predictors of behaviors, this only happens in the case of inward environmental attitude, since outward environmental attitude does not influence environmental behavior. This is in line with previous studies, in which IEA positively influences environmental behavior (Dono et al., 2010; Arslan et al., 2012; Yang \& Weber, 2019). This might be explained by the fact that IEA is an individual attitude, whereas OEA can be seen as a collective action in which outwardly expressed behavior is understood as a public altruistic behavior. As such OEA might display a behavior and not the typical individual attitude. This would also justify why IEA influences environmental behavior so strongly: it is almost a direct translation of a private, individual attitude into an action. The fact that OEA does not influence environmental behavior is also in line with a study performed in Australia, in which it was supported that public external attitudes are not as important as private attitudes since individuals tend to delegate responsibilities to governments and organizations, which leads to less engagement in environmental behaviors, making individuals feel less responsible (Fielding \& Head, 2012). The value-action gap (Vermeir \& Verbeke, 2006) could also be used to justify why individuals are concerned and believe in something, but then fail to act upon it.

Another perspective can be given from the anthropocentric and eco-centric perspectives of IEA and OEA. As individuals believe that the environment needs to be protected they tend to believe more on their IEAs than on the exogenous perspective expressed by OEAs, which depend on major political and social changes, as expressed in the scale used. From an eco-centric perspective, it is clear that individuals are themselves as part of the environment and seek to protect it, but do not rely on social or political changes as drivers of this eco-centric perspectives. As such, one can claim that individuals vis-à-vis social values and attitudes help to explain why IEA positively support environmental behavior and purchase intentions when compared to OEA.

Both inward and outward environmental attitude influence PI, although not very strongly. This is aligned with previous research on IEA (Trivedi et al., 2018). Environmental attitude as a whole was already proven to significantly influence the intention to buy green products (Schwepker \& Cornwell, 1991; Aman at al., 2012; Sun et al., 2018). Other research on the determinants of GPB in China also supports that attitude towards green purchases strongly influences green purchase intention (Chan, 2001). Moreover, different studies using the TPB (Azjen, 1991) in the environmental context, either in sustainable housing purchase or general green products, also present environmental attitude as a strong predictor of green purchase intention (Judge et al., 2019; Choi \& Johnson, 2019). If individuals are willing to reduce consumption and 
participate in activities such as recycling, it seems logic that they would also prefer to buy environmentally friendly products (Trivedi et al., 2018). As people become more aware of environmental problems, it is natural that their attitudes and intentions change, and even those who do not buy ecological products yet, might do so in the future if they are convinced there is an environmental problem (Schwepker \& Cornwell, 1991).

Environmental behavior influences PI significantly, in accordance with earlier studies (Akehurst et al., 2012; Yarimoglu \& Binboga, 2018). It makes sense that, if individuals engage in pro-environmental behaviors, such as separating waste, recycling and reducing overall consumption, they will have higher intention to expand those behaviors to their purchases.

GPB is positively influenced by both EB and PI, in accordance with previous studies (Chan, 2001; Arslan et al., 2012; Trivedi et al., 2018). Similarly to the relationship between EB and PI, if individuals already practice several environmentally friendly behaviors, they are more likely to add one more: purchase behavior. Additionally, Akehurst et al. (2012) concluded that individuals who are already engaged in some kind of environmental behavior tend to purchase more green products than those who expressed an intention to do so.

As this research took place in Portugal, it is important to note that the context under study is notably collectivist and short-term oriented (Hofstede, 1991). As such, in agreement to Halder, Hansen, Kangas, and Laukkanen (2020), this context is characterized by high green consumption values, but people tend to adopt less environmentally and socially sustainable purchasing behaviors, in comparison to those societies that are long-term oriented. The reasoning seems to support our results, since we found strong inward environmental attitudes that are not totally tuned with political and social changes drawn from outward environmental attitudes.

From purchase intention to green purchase behavior, the literature mentions the value-action or intention-behavior gap (Vermeir \& Verbeke, 2006), but several studies show that this relationship is positive, as stated above. This follows the logic of the TPB (Azjen, 1991), according to which behaviors are preceded by intentions. If individuals prefer to buy environmental-friendly products and feel a sense of accomplishment when doing that (Trivedi et al., 2018), they are likely to opt for environmentally friendly products when doing their purchases.

Regarding the differences between men and women, the literature shows that there is still some controversy, although it could probably be explained by cultural differences. In our study, women present higher means for all constructs, supporting the claims by Roberts (1996) and Baker and Ozaki (2008). Although men had been shown to be more ecologically concerned in a very different cultural context (Saleem et al., 2018), the results presented here are aligned with general research (Mohai, 1992; Rahim, et al., 2017). This might be the result of women being socialized to be caregivers, which can lead to an overall concern over various issues, including environmental ones (Mohai, 1992).

When it comes to environmental attitudes, the fact that females scored higher than males is in line with previous research (Mainieri et al., 1997; Diamantopoulos et al., 2003). This can be the result of women having been more actively involved in pursuing affirmative actions, which underpins their activism in environmental sensitive fields.

Regarding environmental behaviors the results are also in agreement with earlier studies, in which women carry out more of these behaviors (Roberts, 1996; Mainieri et al., 1997; Diamantopoulos et al., 2003). 
Women also show higher levels of PI and GPB, which is according to previous research (Roberts, 1996; Mainieri et al., 1997; Rahim, et al., 2017).

\section{Conclusions}

The present study examined the journey to green purchase behavior formation in a holistic manner. The purpose was to understand and empirically investigate the influence of ecological concern on the consumers' purchase behavior of green products.

The data collection was done through an online survey with 530 valid responses. The sample was made up of mostly women.

Of the 15 formulated hypotheses, one was not supported. Overall, the structural model showed strong relationships between variables, which supports that ecological concern, inward environmental attitude, outward environmental attitude, environmental behavior and purchase intention are good predictors of green purchase behavior. Women scored higher than men on all variables, supporting that women are indeed superior environmentalists than men.

Sustainability is a growing concern for enterprises, with many businesses changing their offers, processes, or choosing to invest in green products. Being attentive and adapting to today's environmentally-based, eco-friendly paradigm is important for all businesses, but imperative for the 'green' ones. The results of this paper provide some insights that can be relevant for managers and marketers of green products.

Ecologically-concerned individuals are likely to have both inward and outward environmental attitudes. If green companies target this type of consumers, they can create a larger potential customer database from the beginning and nurture them through the funnel, to later convert them to buyers. This can also help brands create a reputation as environmentally friendly if they engage in campaigns with these ecologically concerned customers. Additionally, attitudes lead to intention, which leads to purchasing. If advertisement awakens environmental attitudes in consumers, this can lead to environmental behaviors that later materialize in green purchases.

Green purchase behavior is strongly influenced by both purchase intention and environmental behavior, so green brands need to be aware that the anthropocentric perspective could be important for individuals who already take some actions towards the environment. However, the eco-centric perspective is also important to embrace eco-centered social values in order for green brands to broaden their reach and be understood as such.

It is important to stress that consumers tend to value their individual behavior strongly, emphasizing inward environmental attitudes that have a great influence on environmental behavior. However, outward environmental attitude, which can be considered a public altruistic behavior, does not influence environmental behavior and marginally affects purchase intention. This means that consumers' attitudes are perhaps being negatively influenced by what consumers expect from the role of government and public authorities regarding public environmental attitudes. As such, future studies need to deepen the relationship between inward and outward environmental attitudes and evaluate how consumers/individuals perceive the role of government and public policies. Furthermore, it would be interesting to address green consumers versus nongreen consumers to assess whether their inward and outward environmental attitudes differ, as well as how they influence purchase intentions and green purchase behavior.

Green marketing requires managers to rethink the whole marketing mix, in order to take into consideration the state of the environment in all stages, from production to disposal. As such, companies need to target their green products/services to the right 
segments, position themselves adequately and communicate properly. Moreover, apart from the regular benefits of the product, the environmental ones should also be showcased.

Finally, it is important to understand that women are very important if green marketing is to succeed. As such, more research needs to be carried out to disclose more specific information regarding type of purchases, type of attitudes towards green and non-green products, as well as how different generations, with different purchasing power, explain different levels of involvement regarding green purchase behavior.

One of the limitations of this paper is that it uses a convenience sample for data collection, which is a limited representation of the population. The fact that this study inquired people about green products in general also brings fewer specific insights. A more in-depth research on a specific type of green products or green brands would translate into more detailed answers.

In the future, it would be useful to conduct a similar study comparing other demographic variables, such as: area of residence, to identify differences between rural and non-rural areas, for example; educational qualifications, to measure if more educated people care more about the environment; or financial situation, to understand to what extent economic power is an antecedent of green purchase behavior. A crosscountry research, comparing different cultures, could also contribute with interesting insights. More specifically, our results, along with the contradictory results found in previous research show the need to deepen the knowledge regarding sociodemographic characteristics of green consumers in different cultural contexts, along with the study of the motives that lead different consumers to think and act green.

\section{References}

Akehurst, G., Afonso, C., \& Gonçalves, H. M. (2012). Re-examining green purchase behaviour and the green consumer profile: new evidences. Management Decision, $50,972-988$.

Albaum, G. (1997). The Likert scale revisited: An alternate version. Journal of the Market Research Society, 39, 331-348.

Aman, L. A., Harun, A., \& Hussein, Z. (2012). The influence of environmental knowledge and concern on green purchase intention the role of attitude as a mediating variable. British Journal of Arts and Social Sciences, 7(2), 145-167.

Arslan, T., Yilmaz, V., \& Aksoy, H. K. (2012). Structural equation model for environmentally conscious purchasing behavior. International Journal of Environmental Research, 6(1), 323-334.

Azjen, I. (1991). The theory of planned behavior. Organizational Behavior and Human Decision Processes, 50, 179-211.

Bailey, I., \& Wilson, G. A. (2009). Theorising transitional pathways in response to climate change: Technocentrism, ecocentrism, and the carbon economy. Environment and Planning, 41, 2324-2341.

Baker, J. P., \& Ozaki, R. (2008). Pro-environmental products: Marketing influence on consumer purchase decision. Journal of Consumer Marketing, 25, 281-293.

Belz, F. M. (2006). Marketing in the 21st Century. Business Strategy and the Environment, $15,139-144$.

Brochado, A., Teiga, N. \& Oliveira-Brochado, F. (2017). The ecological conscious consumer behaviour: Are the activists different? International Journal of Consumer Studies, 41, 138-148. 
Burgh-Woodman, D. H., \& King, D. (2012). Sustainability and the human/nature connection: a critical discourse analysis of being 'symbolically' sustainable. Consumption Markets and Culture, 16, 145-168.

Chan, R. Y. (2001). Determinants of Chinese consumers' green purchase behavior. Psychology \& Marketing, 18, 389-413.

Chang, T.-Z., \& Wildt, A. R. (1994). Price, product information, and purchase intention: An empirical study. Journal of the Academy of Marketing Science, 22, 16-27.

Chen, T. B., \& Chai, L. T. (2010). Attitude towards the environment and green products: Consumers' perspective. Management Science and Engineering, 4(2), 27-39.

Chin, W. (1998). Issues and opinion on structural equation modelling. MIS Quarterly, 22(1), 7-16.

Choi, D., \& Johnson, K. K. (2019). Influences of environmental and hedonic motivations on intention to purchase green products: An extension of the theory of planned behavior. Sustainable Production and Consumption, 18, 145-155.

Curran, P. J., West, S. G., \& Finch, J. F. (1996). The robustness of test statistics to nonnormality and specification error in confirmatory factor analysis. Psychological Methods, 1, 16-29.

De Castro, R. (2001). Naturaleza y funciones de las actitudes ambientales. Estudios de Psicología, 22(1), 11-22.

Deliana, Y. \& Rum, I. A. (2019). How does perception on green environment across generations affect consumer behaviour? A neural network process. International Journal of Consumer Studies, 43, 358-367.

Diamantopoulos, A., Schlegelmilch, B. B., Sinkovics, R. R., \& Bohlen, G. M. (2003). Can socio-demographics still play a role in profiling green consumers? A review of the evidence and an empirical investigation. Journal of Business Research, 56, 465480.

Domanska, E. (2011). Beyond anthropocentrism in historical studies. Historein, 10, 118130.

Dono, J., Webb, J., \& Richardson, B. (2010). The relationship between environmental activism, pro-environmental behaviour and social identity. Journal of Environmental Psychology, 30, 178-186.

Douglas, S. P., \& Craig, C. S. (2007). Collaborative and iterative translation: An alternative approach to back translation. Journal of International Marketing, 15, 30-43.

Dunlap, R. E., \& Jones, R. E. (2002). Environmental concern: Conceptual and measurement issue. In R. E. Dunlap, \& W. Michelson, Handbook of Environmental Sociology (pp. 482-524). London: Greenwood Press.

Dunlap, R., \& Van Liere, K. (1978). The new environmental paradigm: a proposed measuring instrument and preliminary results. Journal of Environmental Education, 9, 10-19.

Elkington, J. (1997). Cannibals with forks: The triple bottom line of 21st century business. Oxford: Capstone.

Fielding, K. S., \& Head, B. W. (2012). Determinants of young Australians' environmental actions: The role of responsibility attributions, locus of control, knowledge and attitudes. Environmental Education Research, 18, 171-186.

Fraj, E., \& Martinez, E. (2006). Influence of personality on ecological consumer behaviour. Journal of Consumer Behavior, 5, 167-181.

Gordon, R., Carrigan, M., \& Hastings, G. (2011). A framework for sustainable marketing. Marketing Theory, 11(2), 143-163. 
Götz, O., Liehr-Gobbers, K., \& Krafft, M. (2010). Evaluation of structural equation models using the partial least squares (PLS) approach. In V. E. Vinzi, W. W. Chin, J. Henseler, \& H. Wang, Handbook of Partial Least Squares (pp. 691-711). Berlin: Springer.

Hair, J. F., Hult, G. T., Sarstedt, M., \& Ringle, C. M. (2016). A Primer On Partial Least Squares Structural Equation Modeling (PLS-SEM). SAGE Publications Inc.

Halder, P., Hansen, E. N., Kangas, J. \& Laukkanen, T. (2020). How national culture and ethics matter in consumers' green consumption values. Journal of Cleaner Production, 265, 121754.

Hasnah, H. S. (2014). The role of islamic values on green purchase intention. Journal of Islamic Marketing, 5, 379-395.

Henion, K. E., \& Kinnear, T. C. (1975). Ecological Marketing (Vol. 168). Wisconsin: American Marketing Association.

Henseler, J., Chin, W. (2010). A comparison of approaches for the analysis of interaction effects between latent variables using partial least squares path modeling. Structural Equation Modeling, 17(1), 82-109.

Hirsh, J. B. (2010). Personality and environmental concern. Journal of Environmental Psychology, 30, 245-248.

Hofstede, G. (1991). Cultures and organizations: Software of the mind. London: McGrawHill.

Hojnik, J., Ruzzler, M. \& Manolova, T. S. (2019). Sustainable development: Predictors of green consumerism in Slovenia. Corporate Social Responsibility and Environmental Management, 27, 1695-1708.

Hu, L.-T., \& Bentler, P. M. (1998). Fit indices in covariance structure modeling: Sensitivity to underparameterized model misspecification. Psychological Methods, 3(4), 424453.

Jansson, J., Marell, A., \& Nordlund, A. (2010). Green consumer behavior: Determinants of curtailment and eco-innovation adoption. Journal of Consumer Marketing, 27(4), 358-370.

Judge, M., Warren-Myers, G., \& Paladino, A. (2019). Using the theory of planned behaviour to predict intentions to purchase sustainable housing. Journal of Cleaner Production, 215, 259-267.

Kahn, K. M., \& Kahn, M. N. (2006). The encyclopaedic dictionary of marketing. New Delhi: Sage.

Katrandjiev, H. (2016). Ecological marketing, green marketing, sustainable marketing: Synonyms or an evolution of ideas? Economic Alternatives, 1, 71-81.

Kaufmann, H. R., Panni, M. F., \& Orphanidou, Y. (2012). Factors affecting consumers' green purchasing behavior: An integrated conceptual framework. Amfiteatru Economic, 14, 50-69.

Kollmuss, A., \& Agyeman, J. (2002). Mind the gap: Why do people act environmentally and what are the barriers to pro-environmental behavior? Environmental Education Research, 8, 239-260.

Lee, K. (2009). Gender differences in Hong Kong adolescent consumers' green purchasing behavior. Journal of Consumer Marketing, 26, 87-96.

Leonidou, C. N., Katsikeas, C. S., \& Morgan, N. A. (2013). “Greening” the marketing mix: do firms do it and does it pay off? Journal of the Academy of Marketing Science, 41, 151-170. 
Leonidou, L. C., Leonidou, C. N., \& Kvasova, O. (2010). Antecedents and outcomes of consumer environmentally friendly attitudes and behaviour. Journal of Marketing Management, 26, 1319-1344.

Mainieri, T., Barnett, E. G., Valdero, T. R., Unipan, J. B., \& Oskamp, S. (1997). Green buying: The influence of environmental concern on consumer behavior. The Journal of Social Psychology, 137, 189-204.

Markert, J. (2004). Demographics of age: Generational and cohort confusion. Journal of Current Issues and Research in Advertising, 26, 11-24.

McCarty, J. A., \& Shrum, L. J. (2001). The influence of individualism, collectivism, and locus of control on environmental beliefs and behavior. Journal of Public Policy \& Marketing, 20(1), 93-104.

Milfont, T. L., \& Duckitt, J. (2010). The environmental attitudes inventory: A valid and reliable measure to assess the structure of environmental attitudes. Journal of Environmental Psychology, 30, 80-94.

Mohai, P. (1992). Men, women, and the environment: An examination of the gender gap in environmental concern and activism. Society \& Natural Resources: An International Journal, 5, 1-19.

Paço, A., \& Raposo, M. (2009). "Green" segmentation: An application to the Portuguese consumer market. Marketing Intelligence \& Planning, 27(3), 364-379.

Paço, A., \& Raposo, M. (2010). Green consumer market segmentation: Empirical findings from Portugal. International Journal of Consumer Studies, 34, 429-436.

Paço, A., Shiel, C., \& Alves, H. (2019). A new model for testing green consumer behaviour. Journal of Cleaner Production, 207, 998-1006.

Panzone, L., Hilton, D., Sale \& Cohen, D. (2016). Socio-demographics, implicit attitudes, explicit attitudes, and sustainable consumption in supermarket shopping. Journal of Economic Psychology, 55, 77-95.

Papadas, K.-K., Avlonitis, G. J., \& Carrigan, M. (2017). Green marketing orientation: Conceptualization, scale development and validation. Journal of Business Research, 80, 236-246.

Papadopolous, I., Karagouni, G., Trigkas, M., \& Platogianni, E. (2010). Green marketing: The case of Greece in certified and sustainably managed timber products. EuroMed Journal of Business, 5, 166-190.

Perera, C., \& Hewege, C. (2018). Climate change risk perceptions among green conscious young consumers: Implications for green commodity marketing. Journal of Consumer Marketing, 35, 754-766.

Pestana, M. H., \& Gageiro, J. N. (2014). Análise de Dados para Ciências Sociais. Lisbon: Sílabo.

Phipps, M., Ozanne, L. K., Luchs, M. G., Subrahmanyan, S., Kapitan, S., Catlin, J. R., \& Weaver, T. (2013). Understanding the inherent complexity of sustainable consumption: A social cognitive framework. Journal of Business Research, 66, 1227-1234.

Preko, A. K. (2017). Analysis of social cognitive model in the context of green marketing: A study of the Ghanaian environment. Business Perspectives and Research, 5(1), 86-99.

Qasim, H., Yan, L., Guo, R., Saeed, A., \& Ashraf, B. N. (2019). The defining role of environmental self-identity among consumption values and behavioral intention to consume organic food. International Journal of Environmental Research and Public Health, 16, 1-22. 
Rahim, R. A., Sulaiman, Z., Chin, T. A., Shoki, M., Arif, M., \& Hamid, M. H. (2017). E-WOM review adoption: Consumers' demographic profile influence on green purchase intention. IOP Conference Series: Materials Science and Engineering, 215, 1-6.

Reisinger, Y., \& Turner, L. (1999). Structural equation modeling with Lisrel: application in tourism. Tourism Management, 20, 71-88.

Roberts, J. A. (1996). Green consumers in the 1990s: profile and implications for advertising. Journal of Business Research, 36, 217-231.

Saha, M., \& Darnton, G. (2005). Green companies or green companies: Are companies really green, or are they pretending to be? Business and Society Review, 110(2), 117-157.

Said, A. M., Ahmadun, F.-R., Paim, L. H., \& Masud, J. (2003). Environmental concerns, knowledge and practices gap among Malaysian teachers. International Journal of Sustainability in Higher Education, 4(4), 305-313.

Saleem, M. A., Eagle, L., \& Low, D. (2018). Market segmentation based on eco-socially conscious consumers'behavioral intentions: Evidence from an emerging economy. Journal of Cleaner Production, 193, 14-27.

Schwepker, C. H., \& Cornwell, B. T. (1991). An examination of ecologically concerned consumers and their intention to purchase ecologically packaged products. Journal of Public Policy \& Marketing, 10, 77-101.

Shaw, D., \& Newholm, T. (2002). Voluntary simplicity and the ethics of consumption. Psychology \& Marketing, 19(2), 167-185.

Sheng, G., Xie, F., Gong, S., \& Pan, H. (2019). The role of cultural values in green purchasing intention: Empirical evidence from Chinese consumers. International Journal of Consumer Studies, 43, 315-326.

Siyavooshi, M., Foroozanfar, A., \& Sharifi, Y. (2019). Effect of Islamic values on green purchasing behavior. Journal of Islamic Marketing, 10, 125-137.

Smola, K. W., \& Sutton, C. D. (2002). Generational differences: Revisiting generational work values for the new millennium. Journal of Organizational Behavior, 23, 363382.

Sony, A., \& Ferguson, D. (2017). Unlocking consumers' environmental value orientations and green lifestyle behaviors: A key for developing green offerings in Thailand. Asia-Pacific Journal of Business Administration, 9(1), 37-53.

Sony, A., Ferguson, D., \& Beise-Zee, R. (2015). How to go green: Unraveling green preferences of consumers. Asia-Pacific Journal of Business Administration, 7, 5672.

Stern, P. C. (1999). Information, incentives, and proenvironmental consumer behavior. Journal of Consumer Policy, 22, 461-478.

Stern, P. C. (2000). Toward a coherent theory of environmentally significant behavior. Journal of Social Issues, 56, 407-424.

Stern, P. C., Dietz, T., Abel, T., Guagnano, G. A., \& Kalof, L. (1999). A value-belief-norm theory of support for social movements: The case of environmentalism. Human Ecology Review, 6, 81-98.

Sun, Y., Wang, S., Gao, L., \& Li, J. (2018). Unearthing the effects of personality traits on consumer's attitude and intention to buy green products. Natural Hazards, 93(1), 299-314.

Tamuliene, V., Kazlauskiene, E., \& Pileliene, L. (2016). Ecologically-conscious consumer purchases in Lithuania. Montenegrin Journal of Economics, 4, 87-96.

Tang, Y., Wang, X., \& Lu, P. (2014). Chinese consumer attitude and purchase intent towards green products. Asia-Pacific Journal of Business Administration, 6, 84-96. 
Trivedi, R. H., Patel, J. D., \& Acharya, N. (2018). Causality analysis of media influence on environmental attitude, intention and behaviors leading to green purchasing. Journal of Cleaner Production, 196, 11-22.

Van Liere, K. D., \& Dunlap, R. E. (1980). The social bases of environmental concern: A review of hypotheses, explanations and empirical evidence. Public Opinion Research, 44, 181-197.

Vermeir, I., \& Verbeke, W. (2006). Sustainable food consumption: Exploring the consumer "attitude-behavioral intention" gap. Journal of Agricultural and Environmental Ethics, 19, 169-194.

Yang, X., \& Weber, A. (2019). Who can improve the environment - Me or the powerful others? An integrative approach to locus of control an pro-environmental behavior in China. Resources, Conservation \& Recycling, 146, 55-67.

Yarimoglu, E., \& Binboga, G. (2018). Understanding sustainable consumption in an emerging country: The antecedents and consequences of the ecologically conscious consumer behavior model. Business Strategy and the Environment, 28, $1-10$.

Zimmer, M. R., Stafford, T. F., \& Stafford, M. R. (1994). Green issues: Dimensions of environmental concern. Journal of Business Research, 30, 63-74. 


\section{APPENDIX A}

\section{Original versions of the scales}

\begin{tabular}{l} 
Scale for Ecological Concern (Trivedi, Patel, \& Acharya, 2018) \\
I am extremely worried about the state of the world's environment and what it will mean for the future \\
generations. \\
Mankind is severely abusing the environment. \\
When humans interface with nature it often produces disastrous consequences. \\
The balance of nature is very delicate and easily upset. \\
Humans must live in harmony with nature in order to survive. \\
Scale for Inward Environmental Attitude (Trivedi, Patel, \& Acharya, 2018) \\
I am very concerned about the environment. \\
I would be willing to reduce my consumption to help protect the environment. \\
I would give part of my own money to help protect wild animals. \\
I have asked my family to recycle some of the things we use. \\
Scale for Outward Environmental Attitude (Trivedi, Patel, \& Acharya, 2018) \\
Major political change is necessary to protect the natural environment. \\
Major social changes are necessary to protect the natural environment. \\
Humans are severely abusing the environment. \\
Scale for Environmental Behavior (Arslan, Yilmaz, \& Aksoy, 2012) \\
I discuss about the environmental problems during the fellow conversations. \\
I throw the wastes by separating. \\
I do not purchase the products of the firms that damage the environment. \\
I try to convince my family members and friends not to buy the products that damage the environment. \\
I have changed my lifestyle in behalf of protecting the nature. \\
I decrease the consumption of electricity, water and fuel in order to protect the nature. \\
I do attend to planting tree. \\
\hline Scale for Purchase Intention (Trivedi, Patel, \& Acharya, 2018) \\
I prefer buying environmentally friendly products. \\
Buying environmentally friendly products have long term benefits. \\
I feel a sense of accomplishment buying eco-friendly products. \\
Scale for Green Purchase Behavior (Trivedi, Patel, \& Acharya, 2018) \\
I buy environmentally friendly products whenever possible. \\
I buy organic food whenever possible. \\
I use products made from recycled materials whenever possible. \\
I recycle household waste, whenever possible. \\
\hline
\end{tabular}

